\title{
A INSERÇÃO DA EDUCAÇÃO PARA O TRÂNSITO NAS ESCOLAS A PARTIR DA INFLUÊNCIA E ORIENTAÇÃO DA GESTÃO ESCOLAR
}

\author{
THE INCLUSION OF TRAFFIC EDUCATION ON \\ SCHOOLS BY THE INFLUENCE AND ORIENTATION OF \\ SCHOOL MANAGEMENT
}

\begin{abstract}
Pedro Ramon Pinheiro de Souza
Doutor em Ciências da Educação pela Facultad Interamericana de Ciencias Sociales hunter4you@gmail.com
\end{abstract}

\begin{abstract}
Resumo: A gestão escolar deve ser uma atividade sistematizada com todos os que fazem a escola, com base em uma educação formativa de natureza permanente; uma educação que foca em pontos essenciais contornada para a mudança e uma proposição de valores éticos e com atenção para a oferta de educação para o trânsito. Assim, objetivou-se analisar a gestão escolar e sua relação com o trabalho docente e a transversalidade impulsionadora da educação para o trânsito. $\mathrm{O}$ percurso metodológico utilizado para atingir o objetivo desta pesquisa científica aplicada foi conduzido através de uma abordagem qualitativa. O referencial teórico construído a partir da pesquisa bibliográfica e documental demonstra que a gestão escolar exerce poder de influência e orientação na construção do material a ser utilizado pelo professor, de maneira que a oferta da educação para o trânsito, de maneira transversal, em sala de aula pode ser aperfeiçoada a partir das iniciativas da gestão escolar.
\end{abstract}

Palavras-chave: Gestão. Educação. Transversal. Trânsito.

Abstract: School management should be a systematized activity with all those who compose the school, based on a formative education of a permanent nature; an education that focuses on essential points circumvented for change and a proposition of ethical values with attention to the provision of traffic education. Therefore, the purpose of this study was to analyze school management and its relationship with teaching work and the propelling transversal nature of traffic education. The methodological approach used to achieve the objective of this applied scientific research was conducted through a qualitative approach. The theoretical framework based on bibliographical and documental research shows that school management wields influence and orientation power in the construction of the material to be used by the teacher, 
so that the provision of traffic education, used in the classroom in a transversal way, can be improved by the initiatives of school management.

Keywords: Education. Transversal. Traffic.

\section{Introdução}

O conceito de gestão se associa ao fortalecimento da democratização do processo de ensino e aprendizagem, exigindo a participação de todos os educadores nas decisões necessárias para influenciar resultados educacionais significativos. A nomenclatura Gestão, no contexto da educação, se expressa no cerne de uma transformação de paradigmas, por meio do reconhecimento de que é importante a participação consciente e esclarecida de todos os educadores nas decisões sobre o planejamento do seu trabalho.

O vocábulo Gestão se consubstancia por meio da tomada de consciência política, revestindo-se, também, de uma consciência crítica acerca da organização de ações que devem ser consolidadas na prática. Os termos Gestão democrática, compartilhada e participativa, embora não se restrinjam ao contexto educacional, se fundamentam na luta de educadores e nos movimentos sociais que embasaram o projeto de educação pública de qualidade e democrática.

A educação é um complexo constitutivo da vida social e das formas de reprodução do ser social, dimensão que contribui para produção e reprodução das condições necessárias ao processo de acumulação incessante do capital (FRIGOTO; CIAVATTA; RAMOS, 2012). A educação é, portanto, um amplo espaço de embates e interesses contraditórios, no qual o capital tem se utilizado como forma de manipulação das massas populares, se revelando como palco onde figuram interesses diversos.

No atual contexto do capitalismo atrelado a ideologia neoliberal, se intensifica o apelo e a busca por estratégias de enfrentamento a sua crise estrutural, tem-se, portanto, a tendência a transformação de todas as esferas da vida social em áreas potencialmente lucrativas, como é o caso da educação (LIMA, 2014). Esta política, pautada na Constituição Federal de 1988 e na 
Lei de Diretrizes e Bases da Educação - LDB no 9.394/96, como direito social, se vê tolhida à adaptação aos ditames do capital, perdendo a noção de oferta como direito social do cidadão, passando a ser encarada como uma mercadoria produzida para comercialização.

Há que se considerar que a lógica neoliberal tende a desconstruir os avanços nas áreas consideradas estratégicas para o avanço da política do capital como é o caso da educação. Assim, os governos Lula e Dilma Rousseff (2010-2014 e 2016), permeados por esta ideologia e assumindo as orientações dos organismos internacionais e às parcerias público-privado, caminharam na direção de, em certa medida, estremecer a educação pública brasileira como um direito social diante da privatização ocorrida em larga escala. No entanto, tudo isso é apresentado pelo governo sob o discurso de "democratização do acesso à educação" para os segmentos mais vulneráveis da população, que se materializa por meio de programas e políticas lançados pelo Estado que busca legitimar suas ações por intermédio de uma eficiente manipulação ideológica: seu verniz democrático popular (PINTO, 2013).

A metodologia contribuiu para a delimitação dos métodos e técnicas que direcionaram a proposta desta pesquisa. A pesquisa qualitativa foi de cunho exploratório, utilizando-se como estratégia de investigação a pesquisa bibliográfica. Em particular, para o desenvolvimento dessa pesquisa foi usada a revisão de literatura: fase de seleção de artigos, livros, revistas, resumos e e-books; a pesquisa documental, com leituras dos documentos encontrados para se detectar a pertinência do conteúdo em relação ao objeto da pesquisa; pesquisa de campo através de entrevistas a gestores e docentes de duas escolas particulares localizadas em áreas de grande fluxo de veículos.

A coerência lógico-estrutural da articulação do raciocínio deste trabalho será apresentada da seguinte maneira: está dividido em três sessões, a primeira trata da introdução; a segunda aborda a concepção sobre gestão e a educação formativa para o trânsito em relação a sua aplicabilidade e a aceitabilidade docente para a inserção da educação formativa para o 
trânsito; a terceira discute as dimensões pedagógicas na relação entre a formação pedagógica e a utilização de temas transversais acerca da educação para o trânsito.

Este artigo é resultado de uma tese de doutorado com pesquisa ainda em andamento que tem por objetivo investigar a prática pedagógica de educação para o trânsito nas Escolas Públicas de Ensino Fundamental da cidade de Mossoró - Rio Grande do Norte - Brasil.

\section{Gestão, Educação Formativa para o Trânsito e sua Aplicabilidade}

A autogestão se traduz no fato de que os órgãos colegiados eleitos de forma democrática exercem autonomia na participação ativa, no debate e no diálogo, em práticas de democracia direta e representativa. Nesse contexto, a autogestão reforça o autogoverno escolar e a autogestão pedagógica. $\mathrm{O}$ autogoverno nas escolas legitima o direito à educação e à democratização nos processos de decisão, relações de poder, práticas educativas e de produção de conhecimento por parte dos profissionais da educação, educandos, famílias e comunidade numa perspectiva de construção sóciocomunitária (LIMA, 2014). No que se relaciona à autogestão pedagógica, diz respeito à diversidade de práticas que envolvem colegiados e conselhos que se integram no seio da escola para tomar decisões.

No que diz respeito à educação, a década de 1990 foi atravessada pelo confronto entre o Estado de Direito Democrático em educação e as tendências de liberalização. Ao se discutir sobre as iniciativas organizativas sobre a Escola, os estudos sobre a participação reforçam a ideologia da decisão democrática. Não obstante, o desenvolvimento da organização da administração da educação foi atravessado por tendências contraditórias que ao mesmo tempo que propagavam a democratização da Administração Pública acatavam os movimentos que indicavam uma tendência neoliberal (LIMA, 2014).

O conceito de gestão se associa ao fortalecimento da democratização do processo de ensino e aprendizagem, exigindo a participação de todos os educadores nas decisões necessárias para influenciar resultados educacionais significativos.

A nomenclatura Gestão, no contexto da educação, se expressa no cerne de uma transformação de paradigmas, por meio do reconhecimento de que é importante a participação 
consciente e esclarecida de todos os educadores nas decisões sobre o planejamento do seu trabalho. Esse vocábulo se consubstancia por meio da tomada de consciência política, revestindo-se, também de uma consciência crítica acerca da organização de ações que devem ser consolidadas na prática (LIMA, 2014).

A Gestão democrática se institui enquanto uma categoria político-educativa, pautada em uma construção social que para ser analisada se precisa entender o contexto histórico, político e participativo, embora não se restrinja somente à compreensão das teorias e modelos que pretendem administrar o contexto educacional, se fundamenta na luta de educadores e nos movimentos sociais que embasaram o projeto de educação pública de qualidade e democrática (LIMA, 2014).

Baseado no exposto anteriormente, a gestão deve ser entendida como um processo político-administrativo na área educacional embasado na associação entre as seguintes dimensões: gestão democrática e eleição, colegialidade e participação na decisão.

A gestão escolar se caracteriza enquanto um componente de cunho social, tendo em vista que a organização escolar possui objetivos diferentes das organizações empresariais, pois no seu seio envolve relações humanas, dentre outras especificidades de ordem pedagógica, política, sociológica e antropológica (LIMA, 2014).

Compreende-se que a gestão educacional é influenciada por teorias da administração científica, particularmente direcionadas tanto para a indústria, quanto para a empresa, destacando-se as ideias de Taylor, que estudou a organização do trabalho, focando na eficiência e produtividade e Fayol, que criou os princípios da autoridade, hierarquia, ordem e unidade (LIMA, 1998).

Motivado por essa influência, se cria a necessidade de inovar o processo de administração escolar, tornando os sistemas adequados aos indivíduos por meio da eleição de um gestor que se torna democrático no seio da escola. Essa democracia diz respeito à tomada de decisões, focando na elaboração conjunta de projetos e na concepção de que as relações 
interpessoais são dinâmicas, exigindo do gestor uma relação mais ativa entre a escola e o seu entorno (LIMA, 2014).

No seio da educação, a gestão democrática faz parte da dinâmica que deve ser efetivada nas escolas, objetivando garantir processos coletivos de participação. Construir uma gestão democrática se integra a luta pela autonomia escolar, tendo em vista a participação efetiva nos processos decisórios da escola. Outrossim, a gestão escolar inclui a implementação de órgãos colegiados nas escolas, como os conselhos diretivos, os quais são representados por docentes, alunos e funcionários. Ainda, existem os Conselhos Gerais, com representação de pais, comunidade e poder municipal (LIMA, 2014).

Conforme Lima (2014, p. 1072), “o poder de decidir, participando democraticamente e com os outros nos respectivos processos de tomada das decisões representa o âmago da democracia $[\ldots .$.$] ".$

Neste aspecto, o poder de decidir é complexo, exigindo atitudes com responsabilidade para que possa garantir o funcionamento da escola como um todo. Alerta-se que um dos maiores desafios do gestor é gerenciar a escola embasado nas motivações dos que dela participam, pois este deve agir com democracia em todos os espaços educativos. Uma das características que o gestor deve ter é saber respeitar os sujeitos que fazem a escola, destacandose dentre estes, pais, alunos e demais educadores. Assim, precisamos de educadores atuantes na escola que saibam respeitar os interesses de todos que a fazem (LIMA, 2014).

Ao repensar a escola, o gestor deve se comprometer com a construção do projeto político pedagógico, planejando e articulando o processo coletivo na tomada de decisões. O Projeto Político - Pedagógico representa novas trilhas para a escola, a qual está alicerçada sobre princípios filosóficos, epistemológicos e pedagógicos. Para a elaboração do PPP a escola é frequentemente desafiada por fatores externos e internos. Os fatores externos são de ordem 
social, econômico-cultural, científica e tecnológica e já os fatores internos dizem respeito ao desenvolvimento do conhecimento sobre o processo educativo (LIMA, 2014).

A missão da escola é oferecer qualidade, ou seja; fazer com que os discentes gozem de uma qualificação, mas para que isso aconteça tem que existir no seio da comunidade escolar uma estrutura que garanta a elaboração e a implementação do planejamento coletivo.

Ao discutir sobre a participação da população na gestão escolar pública, o autogoverno democrático se complexifica por meio de uma feição política em regime de co-decisão e interdependência com outras autoridades públicas (LIMA, 2014). Nesse sentido, existem condicionantes internos (estruturas e procedimentos democráticos), os quais influenciam sobre essa participação.

Sobre os condicionantes, estes se relacionam às condições materiais, físicas e humanas imbricadas às práticas e relações no interior da escola.

Às vezes, quando a gestão é irracional ou se possui o déficit de liderança estes recaem sobre a hierarquia na distribuição da autoridade, pautada em relações verticais de mando e submissão. Nesse sentido, alguns gestores não compartilham com os demais educadores decisões a respeito da escola, classificando-se como uma prática autoritária.

Mas as ações na escola são lentas, porque envolvem interesses imediatos dos indivíduos, os quais produzem conflitos entre os grupos que convivem na escola. Cada indivíduo possui sua cultura, subjetividade e interesses pessoais e profissionais que repercutem sobre a relação de trabalho, fazendo-se necessário que a instituição saiba trabalhar com estes condicionantes (LIMA, 2014).

No interior da escola existem condicionantes ideológicos que retratam as crenças e concepções arraigadas na personalidade de cada pessoa que subsidiam suas práticas, comportamentos e participação na escola.

Voltando à discussão sobre a democratização da gestão nas escolas, se analisa acerca de uma pós-democracia gestionária, um movimento de transformação da administração escolar para a gestão escolar.

Existe uma oscilação entre a centralização das ações na escola e sua descentralização. Essa oscilação denota responsabilidades, mas não inclui a competência na tomada de decisões 
tanto da escola, quanto da comunidade escolar, caracterizando uma ambiguidade e um paradoxo nos conceitos de descentralização e desconcentração nas práticas de gestão escolar, redimensionando as políticas educacionais sem, no entanto, perder a presença do Estado (LIMA, 2014).

Ademais, as escolas se caracterizam enquanto um celeiro de relações sociais, cujos indivíduos interferem de forma direta ou indireta sobre a gestão. Afirma-se que a gestão trata da prática social, estabelecendo no cerne da escola ideias novas que repercutem sobre a dinamização da rede de relações que ocorrem por meio do diálogo entre o contexto interno e externo escolar (LIMA, 2014).

Outrossim, busca-se desenvolver um trabalho em que um novo conceito de cidadania esteja presente nas atividades contextualizadas, reunindo conhecimentos e informações que vão muito além da representação política.

A ética torna-se um princípio educativo não com base em princípios morais para formar pessoas "honestas" ou "caridosas", mas para criar condições para que as identidades se constituam pelo desenvolvimento da sensibilidade e pelo reconhecimento do direito à igualdade (LIMA, 2014).

A escola se caracteriza enquanto uma organização especializada que é laica e controlada pelo Estado, resultando de um processo que teve início em Portugal por meio do Marquês de Pombal. Enquanto organização, a escola secundária se articula por meio de dois modelos: o burocrático e o anárquico.

A escola é uma unidade socialmente construída a partir de um processo social e histórico, se criando como extensão da família para complementar o seu papel. Sobre a escola se integram expectativas, interesses sociais e exigências. Quando se tornou pública, a escola partiu de uma ação vitoriosa por parte do Estado, objetivando garantir o controle sobre a educação. Para poder se tornar laica a escola teria que ser pública (LIMA, 2014).

A partir das análises, identifica-se a importância do gestor frente à administração escolar, partindo de uma visão generalizada. Os resultados apontam avanços, mas implicações na configuração e sistematização da educação enquanto processo formativo, que necessitam de olhar crítico, avaliativo e mudanças. O que provocará abertura para a objetivação de novas 
concepções e práticas instituídas: alicerçadas na reflexão e no diálogo, minimizando, assim, "burburinhos" entre docentes, servidores, gestão, entre os documentos normativos institucionais e, os conflitos entre teoria e prática (LIMA, 2014).

A partir das análises, identifica-se a importância do gestor frente à administração escolar, partindo de uma visão generalizada. Os resultados apontam avanços, mas implicações na configuração e sistematização da educação enquanto processo formativo, que necessitam de olhar crítico, avaliativo e mudanças.

Sendo assim, a proposta para uma gestão que repercuta sobre uma escola de qualidade deverá considerar a participação, construção identitária dos educadores como marco na elaboração de pautas e políticas educacionais. No processo de gestão é relevante que todos se vejam como corresponsáveis para atuar, mediar, expor, propor, elaborar e sugerir configurações para a organização da escola no que diz respeito à consecução das metas e objetivos (LIMA, 2014).

Por fim, almeja-se trazer para o bojo das discussões, sem ter a pretensão de exauri-las, indagações que possam auxiliar a gestão na mudança de uma configuração vertical em gerir a escola. E, assim, atendam tanto à diversidade dos grupos quanto a formação dos estudantes voltada para o respeito e valorização dos direitos humanos, dos (as) docentes, educadores e discentes que, além de incentivar a pesquisa, continuem a revisitar também o fazer e documentos normativos que regem a organização escolar.

\section{Gestão educacional e ética no trânsito: uma proposta a partir dos temas transversais}

Compreende-se que a gestão democrática se fundamenta na participação efetiva de toda a comunidade escolar, ou seja, dos pais, professores, estudantes e demais educadores. A identidade autônoma precisa ser ancorada em competências intelectuais que dão sustentação à análise, solução de problemas, capacidade de tomar decisões, adaptação a novas situações (LIMA, 2014).

Os pressupostos teórico-metodológicos sugeridos para direcionar a interação da educação para a cidadania em sala de aula, espaço esse onde acontecem infinitas interações 
sendo protagonistas da ação educativa professor e aluno, mediados por saberes e fazeres didático-pedagógicos, cuja finalidade é a busca do conhecimento mediatizado pelas elaborações do educando considerando o seu grau de desenvolvimento.

A função do professor é a de operacionalizar procedimentos e aplicar instrumentos que viabilizem o desenvolvimento de um trabalho coletivo e participante de todos os educadores envolvidos no processo de ensino-aprendizagem. Para tanto, a escola deve ser pensada como um conjunto coletivo que seguirá linhas estratégicas que emergem do processo de envolvimento de todos os atores que fazem a educação (LIMA, 2014).

Trata-se das relações de escolarização e desenvolvimento cujas ações são inerentes ao ser humano através de sujeitos e objetos, via educação formal, desse modo, educação e vida não se incluem nem se alternam, mas permanentemente convivem, interagindo entre natureza e sociedade de forma que, na sala de aula, o discente utilize corpo e mente, sentidos e desejos, relações e sonhos, contingências e projetos, na busca incessante pelo conhecimento, na perspectiva de aprender os saberes acumulados através dos legados da humanidade ou até mesmo da tradição oral.

Em grupos organizados, estes se agrupam e se comunicam uns com os outros e assim expressam suas ideias, e ao compartilhar saberes trocam experiências, criando vínculos sociais, afetivos e intelectuais entre eles e o conhecimento. Portanto, no processo educativo o indivíduo e o meio social são dois fatores harmônicos e ajustados, assim, o meio social e/ou o meio escolar se bem compreendidos, devem fornecer as condições pelas quais o indivíduo liberte e realize a sua própria personalidade (LIMA, 2014).

\section{Temas transversais e ética no trânsito}

O controle social é definido como "a participação do cidadão na gestão pública, na fiscalização, no monitoramento e no controle das ações da Administração Pública (CGU, 
2012). Tal definição remete à participação ativa e direta da sociedade civil na gerência da gestão pública.

No Brasil, este conceito ganhou força com a promulgação da Constituição Federal de 1988, também conhecida por “constituição cidadã”, justamente por consagrar como princípio democrático, a participação popular. Tal fenômeno social ocorre, segundo Lock (2004), quando o cidadão, motivado por interesses coletivos e bem comum, busca soluções por vias administrativas ou judiciais.

É possível constatar na Constituição a democracia participativa em seus artigos, a começar pelo disposto no parágrafo único do artigo primeiro responsável por legitimar o povo como real dono do poder estatal, garantindo que o indivíduo possa exercer sua cidadania seja através da democracia representativa ou através da democracia participativa: "todo poder emana do povo, que o exerce por meio de seus representantes ou diretamente" (BRASIL, 1988).

No decorrer de todo o texto constitucional, podem ser localizados outros dispositivos redigidos com base na democracia participativa e na institucionalização da participação popular. Os mecanismos de participação supracitados, podem ser exercidos de forma individual ou coletiva.

Nesse aspecto, se alerta sobre a importância do papel do cidadão na participação democrática junto à comunidade escolar. Especificamente no Brasil, essa percepção vem sendo fortalecida, desde a promulgação da Constituição Federal de 1988, onde foram promovidos avanços capazes de fortalecer a ética. Assim, se propõe que ações sobre a cidadania e a ética sejam propostas no trabalho docente no que diz respeito à temática trânsito.

Abruccio (2007), demonstra a importância do papel dos acadêmicos, intelectuais e das universidades na disseminação nas ações dos programas governamentais. Importa sublinhar, que a sensibilização por meio da educação ainda é passível de bastante investimento, seja didático, seja na forma de projetos de pesquisa e/ou extensão acadêmica. No entanto, é de suma importância a ser considerada e investida, visto que qualificar/capacitar os estudantes promove o aumento da ética e aprimora o canal de comunicação com a sociedade civil. De 
acordo com Wüst e Marcantônio (2014), é através da participação social que os cidadãos tornarse-ão empoderados e aptos a exercerem plenamente seus direitos.

Diante de todas as informações apresentadas, fica clara a importância de instituir uma educação para a ética como forma de fortalecer a democracia e exercitar a cidadania. Ressaltase também, mais uma vez, o papel que a educação exerce no processo de transformação do cidadão, com vias a construção de práticas participativas. Nesse sentido, se propõe trabalhar ética no trânsito por meio de temas transversais no ensino fundamental.

Os Parâmetros Curriculares Nacionais propõem os seguintes temas transversais: ética, cidadania, meio ambiente, pluralidade cultural, saúde, orientação sexual e social, trabalho, consumo e temas locais. Dentre os critérios para que uma das temáticas seja elencada se estabelece a urgência social, abrangência nacional, a participação social, no intuito de aprender conceitos e valores indispensáveis a uma sociedade organizada (BRASIL, 1997).

Os Temas Transversais atravessam os diferentes campos do conhecimento a partir de uma perspectiva transdisciplinar pois questões como a ética no trânsito irão necessitar da contribuição de conhecimentos históricos, das Ciências Jurídicas, da Sociologia, entre outros. (BRASIL, 1997).

O trânsito faz parte da organização da sociedade, sendo considerado tema local nos documentos dos Parâmetros Curriculares Nacionais. Se alerta que essa temática deverá ser trabalhada em todo o território brasileiro, pois o trânsito constitui um problema social grave. Assim, as escolas necessitam educar os indivíduos para serem cidadãos éticos capazes de conhecer e praticar seus direitos e deveres com responsabilidades.

Para se trabalhar com a transversalidade a prática pedagógica deverá ser transformada, ampliando-se o trabalho de formação do aluno. "Os Temas Transversais permeiam necessariamente toda a prática educativa que abarca relações entre os alunos, entre professores e alunos e entre diferentes membros da comunidade escolar". (BRASIL, 1997, p. 30)

Devido ao elevado número de acidentes que repercutem sobre a taxa de óbitos ou sequelas nos indivíduos, a escola precisa promover a reflexão sobre as atitudes das pessoas no trânsito. Reforçando as orientações dos PCNs (1997), o Departamento Nacional de Trânsito DENATRAN publicou em 2009, através da portaria $n^{\circ} 147$, as Diretrizes Nacionais da 
Educação para o Trânsito, estabelecendo que essa temática deve ser trabalhada de maneira transversal tanto na Pré-Escola, quanto no Ensino Fundamental. Assim, a inclusão do trânsito como tema transversal tem como objetivos:

I Priorizar a educação para a paz a partir de exemplos positivos que reflitam o exercício da ética e da cidadania no espaço público;

II Desenvolver posturas e atitudes para a construção de um espaço público democrático e equitativo, por meio do trabalho sistemático e contínuo, durante toda a escolaridade, favorecendo o aprofundamento de questões relacionadas ao tema trânsito;

III Superar o enfoque reducionista de que ações educativas voltadas ao tema trânsito sejam apenas para preparar o futuro condutor;

IV Envolver a família e a comunidade nas ações educativas de trânsito desenvolvidas;

VI Contribuir para mudança do quadro de violência no trânsito brasileiro que hoje se apresenta;

VII Criar condições que favoreçam a observação e a exploração da cidade, a fim de que os alunos percebam-se como agentes transformadores do espaço onde vivem. (BRASIL, 2009, anexo II, p. 2)

Tais objetivos buscam envolver a comunidade escolar e a sociedade, tendo em vista diminuir a violência no trânsito por meio da discussão de atitudes positivas, seguras e éticas.

A transversalidade poderá abordar o trânsito em vários momentos durante o ano letivo, não se restringindo somente ao planejamento de palestras que orientam sobre regras de boa conduta. Cabe salientar que para abordar a ética no trânsito de maneira transversal, os professores podem contextualizar esse assunto com os conteúdos que estão sendo ministrados aos estudantes.

O professor de Matemática, por exemplo, poderá abordar o quantitativo de automóveis nas ruas, alertando sobre a possibilidade de dar carona aos colegas de trabalho como forma de diminuir o número de veículos nas ruas.

Trabalhar a transversalidade vai exigir do professor que planeje aulas dinâmicas e contextualizadas com sua disciplina ou outras afins. Mas, pela necessidade de trabalhar as 
disciplinas obrigatórias que estão no currículo, o trabalho transversal com a temática trânsito poderá não ser realizado.

Assim, é papel do gestor da escola cobrar do professor o que está estabelecido no artigo 76 do Código de Trânsito Brasileiro - CTB "a educação para o trânsito será promovida na pré-escola e nas escolas de $1^{\circ}, 2^{\circ}$ e $3^{\circ}$ graus" (BRASIL, 1997).

\section{A importância da educação para o trânsito no ensino como forma de prevenir e reduzir os acidentes de trânsito}

Dados da Organização Mundial de Saúde (2016) mostram que cerca de 1,25 milhão de pessoas morrem a cada ano em decorrência de acidentes de trânsito e que as lesões e mortes no trânsito são responsáveis por consideráveis perdas econômicas às vítimas, suas famílias e aos países em geral. Essas perdas decorrem dos custos com tratamentos (incluindo reabilitação e investigação do acidente), bem como da redução/perda de produtividade.

O sofrimento humano, combinado com custos globais estimados pela Organização Mundial de saúde em US\$1,850 trilhão ao ano, torna a redução das mortes e das lesões no trânsito prioridade urgente para o desenvolvimento.

Para Araújo (1997) a necessidade de uma conscientização ampla e urgente, sobre educação para o trânsito é visível aos olhos de todos, dada a complexidade dos problemas que surgem no dia a dia de todas as cidades"

O artigo 74 do CTB estabelece que a educação em trânsito é direito e dever de todos os componentes do sistema de trânsito nacional dos estados e municípios. Considerando a importância do trabalho preventivo e consciencioso, o Código de Trânsito Brasileiro também afirma no artigo 76 que a educação para o trânsito será promovida na pré-escola e nas escolas de $1^{\circ}, 2^{\circ}$ e $3^{\circ}$ graus, por meio de planejamento e ações coordenadas entre os órgãos e entidades do Sistema Nacional de Trânsito e de Educação, da União, dos Estados, do Distrito Federal e dos Municípios, nas respectivas áreas de atuação.

A educação para o trânsito no ensino fundamental, estimula os futuros cidadãos a se comportarem de forma consciente e responsável nas vias urbanas e estradas, levando assim aos 
indivíduos a adotarem regras básicas de segurança no trânsito, com objetivo de evitar os acidentes e atender suas necessidades de locomoção.

Dessa forma, tendo em vista que a escola tem o papel, fundamental e intrínseco, de formação cidadã das pessoas e considerando o elevado índice de mortes por acidentes de trânsito, destaca-se aqui a importância que o gestor deve dar a educação para o Trânsito.

\section{Conclusão}

A partir das análises, identifica-se a importância do gestor frente à administração escolar, partindo de uma visão generalizada. Os resultados da pesquisa apontam avanços, mas implicações na configuração e sistematização da educação brasileira enquanto processo formativo, que necessitam de olhar crítico, avaliativo e mudanças. Sendo assim, a proposta para uma gestão que repercuta sobre uma escola de qualidade deverá considerar a participação e a construção da identidade dos educadores como marco na elaboração de pautas e políticas educacionais.

No processo de gestão é relevante que todos se vejam como corresponsáveis para atuar, mediar, expor, propor, elaborar e sugerir configurações para a organização da escola no que diz respeito à consecução das metas e objetivos relacionados ao trabalho e a inserção da educação para o trânsito por meio da transversalidade.

Por meio dessa pesquisa, almeja-se trazer para o bojo das discussões, sem ter a pretensão de exauri-las, indagações que possam auxiliar a gestão na mudança de uma configuração vertical em gerir a escola. E, assim, atendam tanto à diversidade dos grupos quanto a formação dos estudantes voltada para o respeito e valorização dos direitos humanos, da ética, dos docentes, educadores e discentes que, além de incentivar a pesquisa, continuem a revisitar também o fazer e documentos normativos que regem a organização escolar.

Por fim, nota-se, que a gestão exerce poder de influência e orientação sobre os conteúdos, atividades, métodos e abordagens aplicados em sala de aula pelo professor. Sendo assim, levando em consideração que, segundo dados da Organização Mundial de Saúde (2018), acidente de trânsito é a maior causa de morte por acidentes de crianças de 0 a 14 anos, a gestão 
c-ISSN: 2525-3514

deve se utilizar deste poder de influência para orientar e cobrar do professor a inserção da educação para o transito de maneira transversal no conteúdo a ser aplicado em sala de aula com objetivo de conscientizar a crianças.

\section{Referências}

ABRUCIO, Fernando Luiz. Trajetória recente da gestão pública brasileira: um balanço crítico e a renovação da agenda de reformas. Revista de administração pública, v. 41, n. especial, 2007.

ARAÚJO, J. Educação de trânsito na escola. Brasília: DNR - 1997.

BRASIL. Código de Trânsito Brasileiro. 1997. Disponível

em: http://www.denatran.gov.br/ctb.htm. Acesso em: 25 de janeiro de 2019.

BRASIL, Departamento Nacional de Trânsito. Diretrizes Nacionais da Educação para o Trânsito no Ensino Fundamental. Disponível

em: http://www.denatran.gov.br/download/Portarias/2009/PORTARIA DENATRAN_1 47 09 ANEXO II DIRETRIZES EF.pdf. Acesso em: 25 de janeiro de 2019.

BRASIL, Secretária de Educação Fundamental. Parâmetros Curriculares Nacionais. Brasília: MEC/SEF, 1997.

FRIGOTTO, G. Concepções e mudanças no mundo do trabalho e o ensino médio. In: FRIGOTTO, G.; CIAVATTA, M. e RAMOS, M. Ensino médio integrado: concepção e contradições. São Paulo: Cortez, 2012.

LIMA, Licínio C. A Gestão Democrática das escolas: do autogoverno à ascensão de uma pósdemocracia gestionária? Educ. Soc. Campinas, v.35, n¹29, p. 1067-1083, out.-dez, 2014.

LIMA, Licínio C. A escola: uma organização. In: LIMA, Licínio C. A Escola como organização e a participação na organização escolar. Braga: 1998.

ORGANIZAÇÃO MUNDIAL DA SAÚDE. Acidentes de trânsito (folha informativa) 2016 Disponível 
c-ISSN: $2525-3514$

em https://www.paho.org/bra/index.php?option=com content\&view=article\&id=5147:aci dentes-de-transito-folha-informativa\&Itemid=779. Com acesso em: 03/10/2018.

WÜST, Caroline; MARCANTÔNIO, Roberta. Empoderamento Social Local: A vital importância da democracia e da cidadania na construção de políticas públicas municipais. Seminário Internacional de Demandas Sociais e Políticas Públicas na Sociedade Contemporânea, n. 11, 2014.

Recebido em 22 fev. 2019 / aprovado em 04 nov. 2019

\section{Para referenciar este texto}

SOUZA, Pedro Ramom Pinheiro de. A inserção da educação para o trânsito nas escolas a partir da influência e orientação da gestão escolar. Cadernos de Pós-graduação, São Paulo, v. 18,

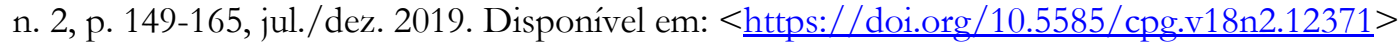

